\title{
Teaching Fluent Handwriting Remediates Many Reading-Related Learning Disabilities
}

\author{
Rowe A. Young ${ }^{*}$, Robert V. Rose ${ }^{2}$, Rand Nelson ${ }^{3}$ \\ ${ }^{1}$ Department of Psychology Program/Behavioral Neuroscience, University of Connecticut Storrs, Storrs, USA \\ ${ }^{2}$ New York University, New York, USA \\ ${ }^{3}$ Indiana University of Pennsylvania, Indiana, USA \\ Email: *roweyk@gmail.com
}

Received 12 August 2015; accepted 13 September 2015; published 16 September 2015

Copyright (C) 2015 by authors and Scientific Research Publishing Inc.

This work is licensed under the Creative Commons Attribution International License (CC BY). http://creativecommons.org/licenses/by/4.0/

(c) (i) Open Access

\begin{abstract}
One of the most vexing educational problems in children is the inability to learn to read. Recently it has been shown that the inability to write skillfully imposes great limits on a child's ability to learn to read. In this paper, information from multiple sources and studies will be reviewed. All of the sources imply a physical (movement) issue is part of the learning problem and emphasize the importance of teaching handwriting skills. Many schools have eliminated all priority and time for instruction of handwriting and college methods courses for teacher training rarely touch on handwriting. The goal herein is to review, for educators and parents, a collection of evidence which strongly indicates that instruction of physical approach skills (i.e., pencil-hold, paper and arm positioning, and body posture) are extremely important. Without identification and correction, maladaptive hand, wrist and arm positions defeat the emergence of fluency and lend to "Reversed Positioning Sensation" (RPS) an invisible condition that affects many students. It is now clear that for RPS children, these skills are critical for literacy to develop. Educators should know that teaching skills for fluent handwriting can be a powerful intervention for children struggling with literacy; and successful instruction in primary classrooms may well prevent development of attention problems and written language disabilities.
\end{abstract}

\section{Keywords}

Handwriting, Dysgraphia, Dyslexia, Reading Disability, Remediation, Learning Support, Special Education

\footnotetext{
${ }^{*}$ Corresponding author.
} 


\section{Introduction}

"Word blindness," which later came to be labeled as dyslexia, was first recognized in Britain near the turn of the $20^{\text {th }}$ century. Dyslexia was reported by Pringle-Morgan in the British Medical Journal on 7 November 1896 . It was believed to be a rare condition in which children, who seemed intellectually normal in every other way, were unable to become literate. Then, in the 1920s, the American psychiatrist Samuel Orton, who had studied neuroanatomy in Europe, published a study showing that this disability affected far more children than previously recognized (Orton, 1925, 1928).

Dr. Orton postulated that this condition was due to the formation of double images - one reversed and the other normal-which were encoded in opposite sides of the brain. He personally devised a treatment for this condition: affected children were to repeatedly write with the dominant hand until only the correct image remained, after which the abnormal reversed image would be suppressed. The use of this handwriting remediation for reading problems achieved notable success with struggling students supporting the theory that a physical (movement) component was a major part of the problem.

Through the years many researchers have identified the important connection between visual motor and auditory connections to reading. In her 1912 English translation of The Montessori Method, the author reported that in her Casa dei Bambini, a pre-school for poor children in Rome, children read "spontaneously" once they had practiced hand motions forming letters of the alphabet. The author considered the children to have reached an “expert” skill level; however "expert” was not defined. Montessori postulated that this skill imparted the ability to "mentally envision”, and hence to remember and make familiar, the paper patterns of correctly spelled written entities (Montessori, 1965). It is interesting to note that the successful method employed by Montessori (hand motions and finger tracing procedures) encouraged the writing hand to be in the same palm-down orientation that is implemented in the Reversed Positioning Sensation (RPS) remedial hand position.

Several years later, Prof. P.G. Aaron at Indiana University published a paper in which he predicted that the term "dyslexia” would soon be abolished (Aaron, 1997). In his paper, Prof. Aaron cited a study (conducted in the Island of Wight and in London, in the UK), that claimed to show that the centers of the Bell Curve for the intelligence quotient (IQ) and for reading skill were different, and that this "discrepancy theory" was the only basis for postulating that some children suffer from an inherent inability to learn to read. However, Aaron (1997) pointed out that the "floor" of the reading test was too high, leading to a false conclusion about the reading skills involved. Hence, no rationale for the disability remains. Over a decade later, Mariecke Longchamp and colleagues of the Universite de la Mediterranee in Marseilles published an article demonstrating that handwriting was statistically superior to typing in learning to name the letters of the alphabet (Longcamp, 2005). Further to the publication of the study by Longchamp et al., Mangen \& Velay (2010) of Stavanger University in Norway also published a free e-book that also emphasizes that practice in learning to write by hand is a valuable educational practice.

In 2012, Marilyn Jager Adams, a famous authority on literacy instruction and author of the influential book Beginning to Read (Adams, 1994), published what is arguably her most important book on education, $A B C$ Foundations For Young Children (Adams, 2012). Adams' book focuses on how to teach children to write the alphabet, and which "sounds"-or phonemes - the letters of the alphabet represent. Dr. Adams commented in the introduction that the majority of American children finishing Grade 1 still cannot write and name all of the letters of the alphabet. Adams further states that the inability to distinguish between different letters is a great impediment to literacy acquisition, with the greatest problem in children living in poverty, where parents are less likely to teach writing in the home.

Research has also shown that the inability to write skillfully imposes the greatest limits on a child's ability to compose written essays, and that writing practice in early grades improves this ability (Graham, 2010). The latest research further demonstrates that handwriting is important for the early recruitment of letter processing in brain regions that are known to underlie successful reading (Richards, 2015). The evidence indicates that proficient handwriting facilitates reading acquisition in young children.

Herein we describe a collection of evidence which strongly indicates that instruction of physical approach skills (i.e., pencil-hold, paper and arm positioning, and body posture) are critical for the development of literacy.

\section{Physical Language}

In 1987 Young \& Ginsburg observed that children with learning disabilities often cannot feel the motion of a 
writing hand normally, and that when making a clockwise circle with a pencil, the feeling is described as if the pencil point is moving in a counter-clockwise direction (Young \& Ginsberg, 1987).

Further studies by these authors showed that a majority of youngsters diagnosed as "learning disabled" (i.e., dyslexic, attention deficit hyperactivity disorder, and Written Language Disability [WLD]), described the same phenomena (Young \& Ginsberg, 1993). These authors observed a similar type of rotational movement reversal in learning disabled children who unscrewed bottles in an atypical way: the subjects held the bottle cap in place with one hand while twisting the bottle from below with the other hand to separate the top from the bottle (or, the subject preferred using just the left hand on top). The "bottom-rotation" or "exclusive-left" approach is the opposite of the procedure used by the majority of children to perform this activity. These behaviors have since been named RPS. The authors also noted that subjects employed unusual positions for fingers, hands, wrists, and arms when attempting to write.

As a result of these observations, Young et al. subsequently demonstrated that by changing the handwriting posture (pencil-hold, paper-hold, and hand/arm positions) the sensation of RPS was eliminated and students who accomplished the complete physical transition were able to achieve writing proficiency (Young et al., 2012). The technique utilized—labeled as a "remediation grip" by Nelson (2015)—involved holding a pencil with the barrel between index and middle fingers, rather than the more common way of holding the pencil with the barrel next to the index finger and supported by the thumb in the space between those two digits. This more common hold posture is sometimes referred to as a "tripod grip" (i.e., three fingers hold the tool, similar to the way a spoon would be held). The remediation grip (also called a "glass cutter grip") causes the writer to turn the palm towards the table and the paper more than is typical with the "tripod" hold. This change of hand position enables affected children to feel (and also learn) the correct movement direction needed to form the alphabet on paper because physical sensations will now match the visual input during instruction and practice. However, in the study by Young et al. (2012), because of the unnatural new position, only students who were correctly taught to permanently change positions were able to be helped.

\section{Description of Reverse Positioning Sensation}

It is most important to understand that for those who are able to sense it, handwriting movement can have a "top or front movement side" and a "bottom or back movement side".

This can be better understood by imagining a plexiglass marker board in a classroom. A teacher places a visual image of a letter such as a "b" on the front side of the display and asks a pupil to trace the image. The child sees and feels the front or topside of the movements. But, if a student walked to the back side of the board to trace the image showing through, the student would be sensing the back or bottom side of the movement. The show-through image is a reversed, mirror image.

Now take the letter-tracing exercise to the desk with a piece of paper. The teacher asks the pupil to look at the letter "b" and the child sees the front/top side of the image. The teacher asks the child to trace the image of the letter with a crayon or pencil, which is one of the most common learning activities for primary grade children. If the child holds the tool properly with the palm facing the page and the pointer finger on top of the pencil, the child is able to feel the topside of the movement process. The movement sensation matches the visual input for the shape when creating the letter.

Those with RPS syndrome are working with an "inverted" hand position, which puts the controlling fingertips under the pencil. The RPS subjects report feeling the pencil pressure with the finger that was under the pencil. Visual input is the front/top side of the movement ("b") but physical input is sending the backside ("d") of the movement from the fingertips on the under-side of the pencil. While visual and physical input for all letters might not be as intensely opposite as the letter "b", enormous difficulty in learning (internalization), and associating all letters with sounds, is presented by the mixed haptic (tactile) input. The confusion is presented by every letter movement sequence, but it is particularly intrusive when trying to learn the majority of the letters that are built with rotational strokes.

When first learning to shape individual letters and connect sight to the sound and feeling of shapes, the mixed sensory input sets the stage for attention problems and confusion when the student is challenged to learn and use written language. This is why these otherwise generally intelligent students have such difficulty learning the written word and attending to the task. This is also why these students are so often misunderstood, and why teachers find it so difficult for these students to successfully develop written language proficiency (Young, 2015). 
However, research is now "showing that letter perception is facilitated by handwriting experience, further suggesting that handwriting fluency is important for letter processing in the brain”. For this reason, awareness of this learning difference (RPS), and the need for handwriting process instruction that can prevent it, needs to become widely recognized by parents and educators.

\section{Handwriting Disability Correlation}

After the findings of Young \& Ginsburg were published in 2012, Young was contacted by Rand Nelson, the president of Peterson Directed Handwriting. Nelson had decades of experience working in hundreds of elementary classrooms throughout the US as a handwriting specialist.

The unique Peterson Handwriting teaching strategy is movement-based which necessitates mastery of physical position skills that are a critical part of the learning. Mr. Nelson recognized in the Young et al. paper describing RPS, a strong relevance to many of the problems he and other Peterson specialists frequently encountered. These traveling handwriting specialists were constantly asked to help students who were struggling with handwriting in particular, and associated written language skills as a result.

Nelson and the other Peterson specialists had long been teaching a "remedial grip" that would allow children to learn to write normally, thereby becoming literate in written language. Both Nelson and Young independently, from two different perspectives (experience and research, respectively), discovered that the same change of handwriting postures provided remediation for students struggling with handwriting and the condition now known as the RPS syndrome.

\section{Handwriting Fluency and Writing Correlation}

Several years prior to the Young et al. paper published in 2012, Nelson met a retired medical doctor (Robert V. Rose) who was actively working to promote handwriting fluency as a solution to written language difficulties and illiteracy. Because the Peterson method included fluency as a goal, and constantly promoted assessment of handwriting fluency as an important part of the teaching task, Nelson and Rose immediately began to work together to promote instruction of handwriting fluency. Dr. Rose was subsequently introduced to Young and the RPS study, and Young was introduced to the study published by Dr. Rose in 2004 (The Writing/Reading Connection) (Rose, 2004).

Nelson published the Rose paper on the Peterson Directed Handwriting web site and subsequently worked with Rose to recruit new teachers to repeat the original work on two more occasions. Data from new teachers and students showed the same results. Dr. Rose and the volunteer teachers demonstrated that if children in kindergarten or Grade 1 practiced writing the alphabet until they achieved a minimal rate of 40 letters per minute, they were reading at or above grade expectations as judged by the teacher. Rose completed his study with online teachers, and his paper, “The Writing/Reading Connection” may be found on the Peterson Handwriting website. It is also available on the web site of Don Potter (2014).

\section{Looking at the Brain with Functional Magnetic Resonance Imaging (fMRI)}

An extremely important connection between handwriting and reading was also demonstrated by James et al. (2012) in preliterate children using fMRI. The authors demonstrated that the act of producing a letter by hand stimulated the "reading circuit" in subjects while tracing and typing did not stimulate that previously identified circuit.

During the 2012/2013 school year, approximately 13\% of schoolchildren in the United States were taught in special education classrooms (National Center for Education Statistics, 2015). The 2013 National Assessment of Educational Progress report on reading assessments showed that 32\% of Grade 4 students scored below basic proficiency and 22\% of Grade 8 pupils scored below basic proficiency (National Assessment of Educational Progress, 2013). The reading results look more dismal when another $40 \%$ of pupils, scoring at or slightly above basic proficiency, were added to the non-literate total. Less than $40 \%$ of Grade 8 children tested are shown to be proficient readers.

Some of the more recent fMRI findings comparing children with and without dyslexia or dysgraphia or no found learning disabilities, have found significant neurological differences between these groups (Richards et al. 2015). 


\section{Correlating Handwriting Capability and Reading Fluency}

The Random Automatic Letter Naming Scores (RAN/Letters) assessment, sometimes called DIBELS Letter Naming Test (Kaminski, 2007), is a timed writing assessment of letter naming fluency. Children are asked to name as many randomly presented letters as possible in one minute. A score of 40 letters per minute (LPM) is widely accepted as a predictor of future literacy success.

The handwriting fluency test, as developed by Rose, is also a timed assessment. It is used to measure the handwriting production rate. Children are asked to write the alphabet in order during a short timed interval. The score is presented as the LPM. The LPM activity was used by teachers in the Rose study to measure the individual handwriting production rate as an indicator of "level of expertise" or fluency.

An on-going study by Nelson is comparing RAN/Letters with handwriting fluency scores (LPM), to provide further evidence of a connection between fluent handwriting skills and the development of reading ability. Home school Magazine (2014) recently published a review article about the work and showed graphs produced from data that had been collected to date.

Nelson theorizes, as proposed by Dr. Rose, that RAN/Letters scores would parallel and exceed LPM scores. Data collected on several hundred Grade $1(n=167)$ and Grade $2(n=132)$ children clearly supports the theory. Nelson's data was collected in March 2014 by teachers who began to use a movement-based strategy for precise handwriting process instruction in 2013. This was undertaken with a new and higher priority for handwriting instruction. The Grade 2 data seems to show that a major difference in skill level was achieved by the curriculum change. If teachers had collected scores in the fall, for comparison with these individual scores collected in the spring, this effort may have been able to shown causation. However, the Grade 1 average naming score from this data is nearly 60\% higher than the average Grade 2 RAN/Letters, as illustrated in Figure 1 and Figure 2.

Figure 1 represents the letter-naming rate (in blue) and the letter writing rate (in orange) for the Grade 1 subjects. Individual subjects, are represented by the numbers running horizontally across the bottom of the chart. Scores ascend from zero along the vertical axis. Subjects were sorted in ascending order for letter-writing rate so the orange line climbs smoothly across the chart. While the blue lines jump up and down to show individual RAN/Letters; note how few times the blue bar (RAN/Letters) drops below the orange bar (letter-writing score).

The Grade 2 subjects represented in Figure 2 were also sorted in ascending order of writing fluency. The orange line again represents individual LetterWriting Scores. Scores ascend along the vertical axis. The blue bars represent the individual RAN/Letters. The Grade 2 subjects went through Grade 1 before the movement-

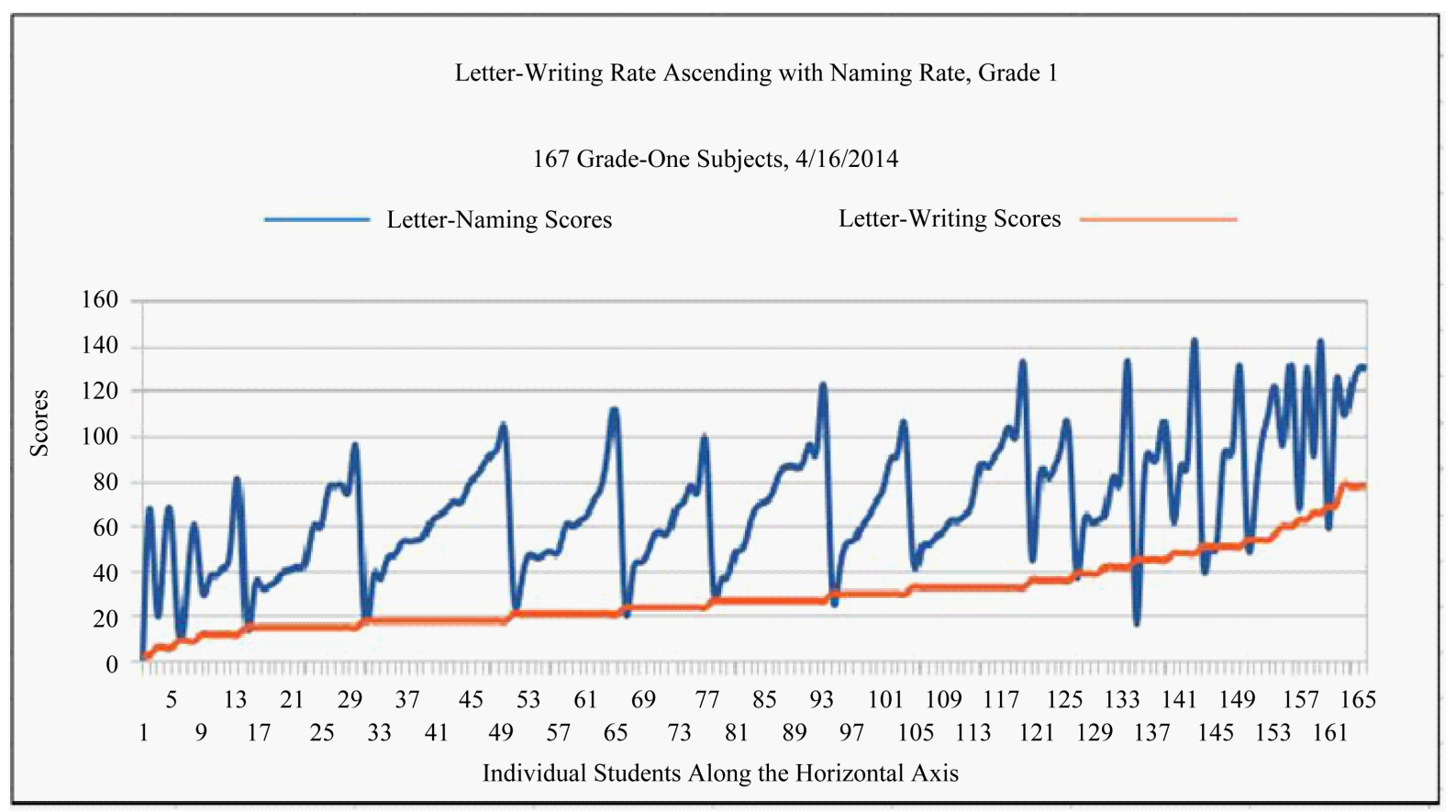

Figure 1. Grade 1: letter-writing rate ascending with letter naming rate. 


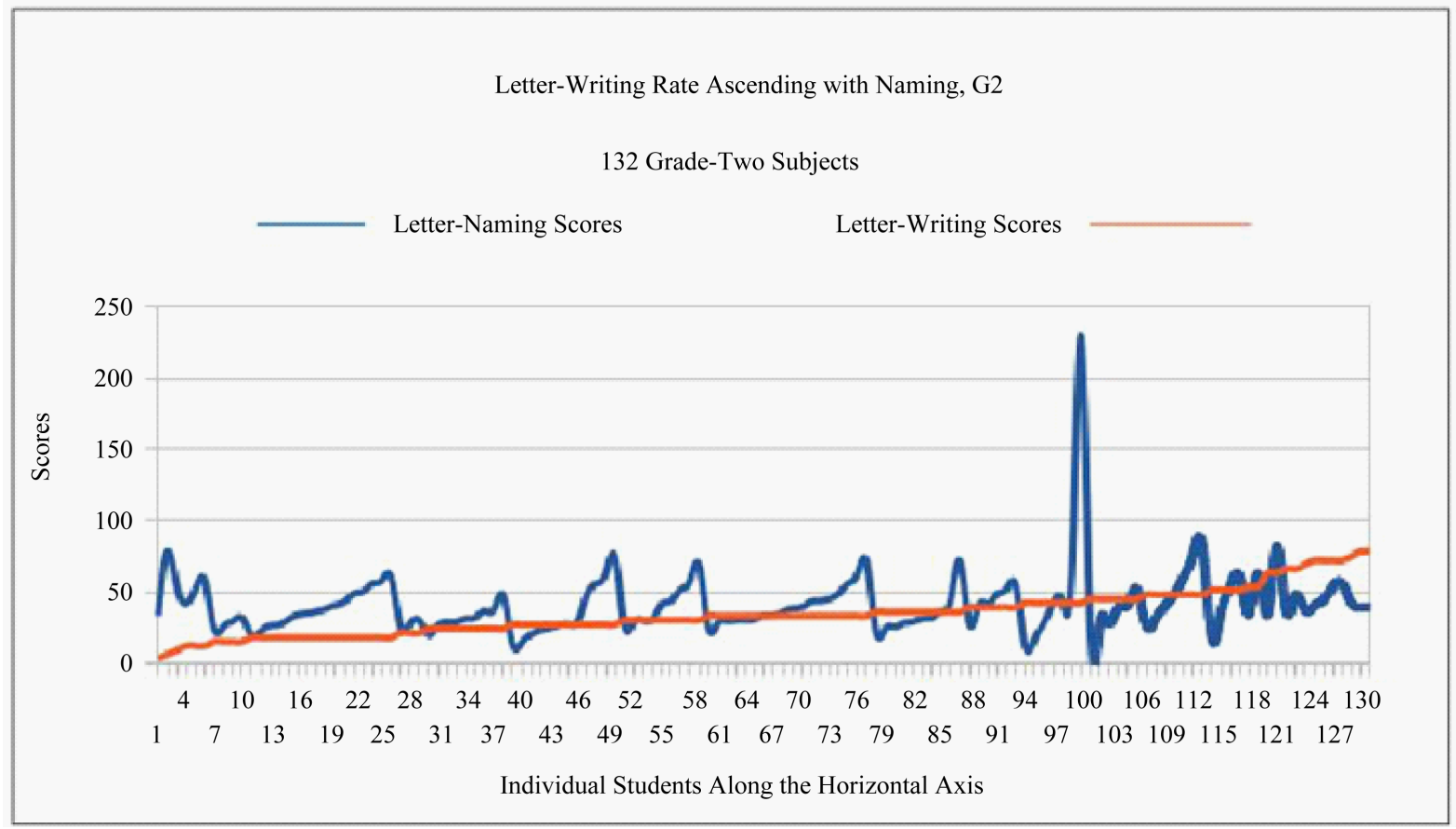

Figure 2. Grade 2: letter-writing rate ascending with naming rate.

based training for handwriting was adopted and the priority for handwriting instruction was restored. Their learning experience consisted largely of independent trace and copy activities.

\section{Comparing Grade Level Average Scores}

Comparison of average RAN/Letters between school grades is rather startling; Grade 1RAN/Letters are $>60 \%$ higher than Grade 2. The Grade 1 handwriting scores are only slightly lower than Grade 2 (Table 1).

\section{Discussion}

Evidence from reported test scores indicates that there is a need for a major change in our schools at all grade levels. A study by Virginia Berninger, a psychologist who heads the University of Washington Learning Disabilities Center, showed that in children (Grades 2 - 5), writing by hand was associated with better phenome skills, spelling, and idea expression, compared with typing on a keyboard, indicating a brain basis for these different disabilities (Berninger, 2006).

Minimal time is spent teaching skills for handwriting, even in primary grades, despite a growing body of research indicating that the omission of physical instruction for handwriting is setting the stage for academic failure for many children. As Richards and colleagues (2015) have also suggested, based upon the neurological differences found in students with different types of disabilities, each case needs to be individually addressed.

To stimulate changes in the schools there is dire need for cooperation between teachers and researchers. If there is to be hope of demonstrating conclusively that handwriting and reading skills are linked by fluency, researchers need data from teachers. If there is to be hope that people with written language disabilities can be helped, researchers need input from teachers. Teachers frequently complain about the amount of teaching time used for testing that serves no real purpose beyond data for government publications. Most teachers deflect requests for study participation because they feel assessments take away too much teaching time.

However, a collection of data for letter naming fluency and handwriting fluency (as the school year begins, and again as the school year ends) for a significant number of primary students would show change for individual subjects. If this fluency connection were shown to be causative, teachers could gain a great deal of teaching time. A simple 30-second, timed-writing group exercise could be employed regularly to track student progress in learning written language skills while enabling evidence-based coaching to improve individual skills. 
Table 1. Comparison of letter naming and writing scores (Grade 1 and Grade 2).

\begin{tabular}{ccccc}
\hline \multirow{2}{*}{ Elementary School Grade } & \multicolumn{2}{c}{ Letter Naming } & \multicolumn{2}{c}{ Letter Writing } \\
\cline { 2 - 5 } & RAN/Letters & Median & LPM & Median \\
\hline Grade 1 & 71.2 & 68.5 & 31.9 & 27 \\
Grade 2 & 41.38 & 38.63 & 34.58 & 33 \\
\hline
\end{tabular}

LPM, letters per minute; RAN/Letters, Random Automatic Letter Naming Scores.

\section{Conclusion}

Proper identification of individual writing instruction needs, along with the impact of RPS testing and remediation on the Learning-Support population could be quantified if teachers would be willing to collect and share relatively simple data. The same simple timed handwriting exercise, documented with some regularity, could lead to better understanding for all.

A steadily increasing number of learning problems is plaguing our schools and breaking school budgets. Solutions to those problems could come from the classroom if teachers would invest a minimal amount time to gather data and share it with researchers. The Internet now opens superb channels for cooperation in a very timeefficient and cost-effective way.

\section{Acknowledgements}

The authors would like to thank Penny Baron, MS and James Kaple, PhD for editorial assistance in the preparation of this manuscript.

This article is dedicated to the memory of Dr. James Kaple, whose tireless commitment, perseverance and enthusiasm toward, and support of, my research efforts helped brighten my path and provide the energy and light to move boldly forward. (Rowe-Young Kaple; August 21, 2015).

\section{References}

Aaron, P. G, \& Joshi, M. (1997). The Impending Demise of the Discrepancy Formula. Review of Educational Research, 67, 461-502. http://dx.doi.org/10.3102/00346543067004461

Adams, M. J. (1994). Beginning to Read: Thinking and Learning about Print. Cambridge, MA: The MIT Press.

Adams, M. J. (2012). ABC Foundations for Young Children: A Classroom Curriculum Children and Youth with Disabilities, National Center for Educational Statistics (2011-12). https://nces.ed.gov/programs/coe/indicator cgg.asp

Berninger, V. W., Abbott, R. D., Jones, J., Wolf, B. J., Gould, L., Anderson-Youngstrom, M., Shimada. S., \& Apel, K. (2006). Early Development of Language by Hand: Composing, Reading, Listening, and Speaking Connections; Three Letter-Writing Modes; and Fast Mapping in Spelling. Developmental Neuropsychology, 29, 61-92.

http://dx.doi.org/10.1207/s15326942dn2901 5

Don Potter (2014). http://www.donpotter.net/education_pages/.

Graham, S. (2010). Want to Improve Children's Writing? Don’t Neglect Their Handwriting. American Educator. http://www.aft.org/sites/default/files/periodicals/graham.pdf

James, K. H., \& Engelhardt, L. (2012). The Effects of Handwriting Experience on Functional Brain Development in Pre-Literate Children. Trends in Neuroscience and Education.

Kaminski, R. A., \& Cummings, K. D. (2007). Assessment for Learning: Using General Outcomes Measures. Threshold, DIBELS, Letter Naming Fluency Test, 26-28. http://dibels.uoregon.edu/

Longcamp, M., Anton, J. L., Roth, M., \& Velay, J. L. (2005). Premotor Activations in Response to Visually Presented Single Letters Depend on the Hand Used to Write: A Study on Left-Handers. Neuropsychologia, 43, 1801-1809. http://dx.doi.org/10.1016/j.neuropsychologia.2005.01.020

Mangen, A., \& Velay, J. L. (2010). Digitizing Literacy: Reflections on the Haptics of Writing. In M. H. Zadeh (Ed.), Advances in Haptics.

http://www.intechopen.com/books/advances-in-haptics/digitizing-literacy-reflections-on-the-haptics-of-writing www.intechopen.com

Montessori, M. (1965). Dr. Montessori’s Own Handbook: A Short Guide to Her Ideas and Materials. New York: Schocken Books. 
National Assessment of Educational Progress (NAEP) (2013). The Nation’s Report Card. What Proportions of Student Groups Are Reaching Proficient? http://www.nationsreportcard.gov/reading_math_2013/\#/student-groups

National Center for Educational Statistics (2015). Reading Performance. https://nces.ed.gov/programs/coe/indicator_cgg.asp

Nelson, R. (2015). Remedial Grip Movie. http://www.youtube.com/watch?v=rtjGvPV5fCg

Nelson, R. H. (2014). Handwriting and Reading, Is There a Connection? Homeschool Magazine, 18, 28-29.

Orton, S. T. (1925). "Word Blindness” in School Children. Archives of Neurology and Psychiatry, 14, 581-615. http://dx.doi.org/10.1001/archneurpsyc.1925.02200170002001

Orton, S. T. (1928). Specific Reading Disability—Strephosymbolia. JAMA, 90, 1095-1099. http://dx.doi.org/10.1001/jama.1928.02690410007003

Richards, T. L., Grabowskia, T. J., Boord, P., Yagle, K., Askren, M., Mestre, Z., Robinson, P., Welker, O., Gulliford, D., Nagy, W., \& Berninger, V. (2015). Contrasting Brain Patterns of Writing-Related DTI Parameters, fMRI Connectivity, and DTI-fMRI Connectivity Correlations in Children with and without Dysgraphia or Dyslexia. NeuroImage: Clinical, 8, 1-31. http://creativecommons.org/licenses/by-nc-nd/4.0/ http://dx.doi.org/10.1016/j.nicl.2015.03.018

Rose, R. V. (2004). The Writing/Reading Connection. http://www.peterson-handwriting.com/teacher support/Research-teachersupport.html

Young, R. A. (2015). Effects of Physical Rotational Movement Difference and Handwriting Position on Academic Achievement and Learning Disabilities. Psychology, 6, 243-250. http://dx.doi.org/10.4236/psych.2015.63024

Young, R. A., \& Ginsburg, B. E. (1987). Genetic Variations in Motor and Cognitive Patterns Associated with Reading Disabilities-Diagnosis and Remediation. Behavior Genetics, 17, 644.

Young, R. A., \& Ginsburg, B. E. (1993). The Directional Motor Link in Reading Disabilities. In Temporal Information Processing in the Nervous System: Special Reference to Dyslexia and Dysphasia. Annals of the New York Academy of Sciences, 682, 436-439. http://dx.doi.org/10.1111/j.1749-6632.1993.tb23016.x

Young, R. A., Ginsburg, B. E., \& Bradway, D. (2012). Physical and Behavioral Markers Help Identify Written Language Disability (WLD) Related to Attention Deficit Hyperactivity Disorder (ADHD). Psychology, 3, 36-44.

http://dx.doi.org/10.4236/psych.2012.31006 